\title{
The ideal technique for processing SpyBite tissue specimens: a prospective, single-blinded, pilot-study of histology and cytology techniques $\square$
}

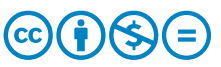

\author{
Authors \\ James G. Kench², Payal Saxena' ${ }^{1}$, Arthur J. Kaffes ${ }^{1}$ \\ Institutions \\ 1 AW Morrow Gastroenterology and Liver Centre, Royal \\ Prince Alfred Hospital, Sydney, Australia \\ 2 Department of Tissue Pathology and Diagnostic \\ Oncology, Royal Prince Alfred Hospital, Sydney, Australia
}

Judith E. Baars ${ }^{1}$, Mathew Keegan ${ }^{1}$, Mark H. Bonnichsen ${ }^{1}$, Patrick Aepli ${ }^{1}$, Ruben Theyventhiran ${ }^{1}$, Elizabeth Farrell ${ }^{1}$,

submitted 18.2.2018

accepted after revision 8.10 .2018

\author{
Bibliography \\ DOI https://doi.org/10.1055/a-0950-9554 | \\ Endoscopy International Open 2019; 07: E1241-E1247 \\ (c) Georg Thieme Verlag KG Stuttgart · New York \\ eISSN 2196-9736
}

Corresponding author

Dr. Arthur Kaffes, Suite G10, RPA Medical Centre,

100 Carillon Ave, Newtown, NSW 2042, Australia

Fax: +61295160778

arthur@kaffes.com

\section{ABSTRACT}

Background and study aims Diagnostic sensitivity for indeterminate biliary lesions remains suboptimal. Cytology techniques may mitigate the impediment of small cholangioscopic specimens. Our primary aim was to compare cell block cytology (CB) with standard histology for foregut
SpyBite (SB) specimens. Our secondary aim was to assess CB in biliary SB biopsies.

Patients and methods This was a two-phase prospective pilot study. In phase one, a prospective pilot study, foregut SB specimens from three sites (4 per site per patient per processing technique) were allocated to $C B$ or histology, and assessed by a single, blinded pathologist. The gold standard comprised two standard forceps (CFB) histological specimens per site per patient. Specimen ease of processing, size and number, adequacy for diagnosis and artefact were evaluated. In phase two, CB was used for consecutive patients with indeterminate biliary lesions, and compared with phase one $\mathrm{CB}$ results.

Results In phase one, 240 SB foregut biopsies were performed in 10 patients, 227 specimens recorded by pathologist. Specimen origin was identified in $100 \%$ and $97 \%$ of histology and CB batches respectively. Specimens were significantly larger in the histology group $(2.02 \mathrm{~mm}$ vs $1.49 \mathrm{~mm}, P<0.05)$. There was a trend to less crush artifact with $C B$, and no difference in processing difficulty. In phase two, 11 patients $(63.0 \pm 12.7$ years, $91 \%$ female) underwent SpyGlass (SG) assessment of suspected indeterminate stricture $(n=8)$ or mass $(n=3)$, and six underwent SB. All CB specimens were adequate for diagnosis. Specimen parameters were not significantly different from luminal CB outcomes. Conclusions In this pilot study, cell block cytology showed similar results as histological analysis of SpyBite specimens in the analysis of biliary stricture.

\section{Introduction}

Indeterminate biliary strictures are an important clinical problem of which approximately $70 \%$ are malignant [1]. In onefourth of suspected malignant strictures that are managed surgically, histopathology appears to be benign [2]. While unnecessary surgery is an important concern due to significant morbidity and mortality rates for upper gastrointestinal surgery, even in high-volume centers, false negatives pose an even greater concern [3]. Specificity for malignancy is universally high across diagnostic methods, however, sensitivity for cytolo- gy and biopsy is inadequate and variable ranging from $15 \%$ to $72 \%$ [4-8]. Augmented sensitivity has been demonstrated with multimodal sampling including brush cytology, biopsy after mucosal disruption, and when aneuploidy is demonstrated with fluorescent in situ hybridization (FISH) [9-12]. The role of endoscopic ultrasound (EUS) in indeterminate biliary lesions is limited to distal mass lesions with variable sensitivity ranging from $25 \%$ to $89 \%$ [ $13-15]$.

The SpyGlass Direct Visualization System (SG) (Boston Scientific Endoscopy, Natick, Massachusetts, United States) allows for lesion visualization and targeted biopsy. The Spybite biopsy 
forceps (Boston Scientific Endoscopy, Natick, Massachusetts, United States) is indicated for tissue acquisition in the pancreaticobiliary system.

Previously described cholangioscopic features of malignancy facilitate targeted biopsy of lesions [16-20]. However, the small size of SpyBite (SB) specimens has led to reports of processing difficulties [23]. Overcoming the processing difficulties posed by small SB specimens is central to supporting the clinical utility of cholangioscopically guided biopsies. Video 1 shows the endoscopic image of a suspicious malignant biliary stricture. It demonstrates villous appearance with altered vascularity and normal bile duct tissue in the background. \ Fig. 1 demonstrates cold forceps biopsy of this lesion.

The primary aim of this study was to compare CB and histology processing of SB foregut specimens. The secondary aim was to compare outcomes of CB processing of SB biliary specimens with those from luminal SB specimens processed by $C B$.

\section{Patients and methods}

This study consisted of two phases. Phase one was a prospective, single-blinded, pilot study for the comparison of two tissue processing techniques ( $C B$ and standard histopathology) for SB samples from the upper gastrointestinal tract in outpatients presenting for upper gastrointestinal endoscopy. In phase two, the CB tissue processing technique was utilized for consecutive patients presenting for SG examination of indeterminate biliary lesions.

\section{Phase one}

\section{Patient population}

Consecutive patients over the age of 18 who presented for diagnostic endoscopy and were able to give informed consent were included. Patients who presented for an endoscopy for ac-

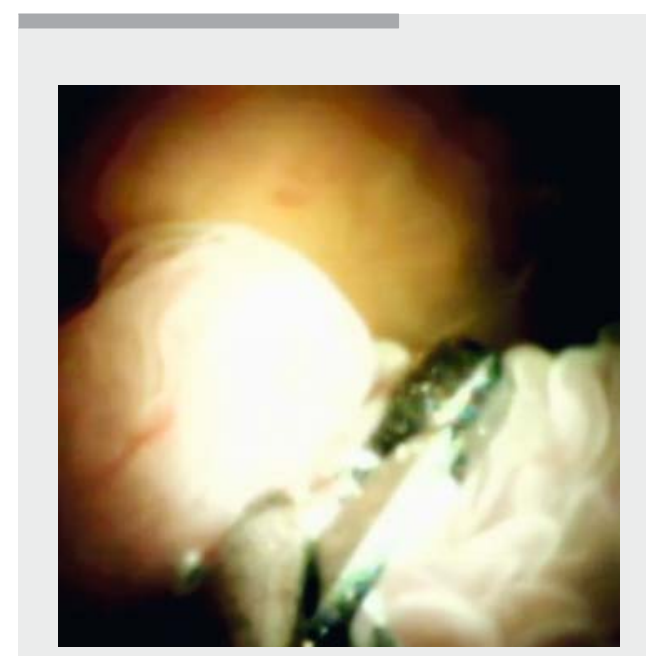

Video 1 endoscopic image suspicious malignant biliary stricture. Video one shows the endoscopic image of a suspicious malignant biliary stricture. It demonstrates villous appearance with altered vascularity and normal bile duct tissue in the background.
10 patients undergoing routine upper Endoscopy

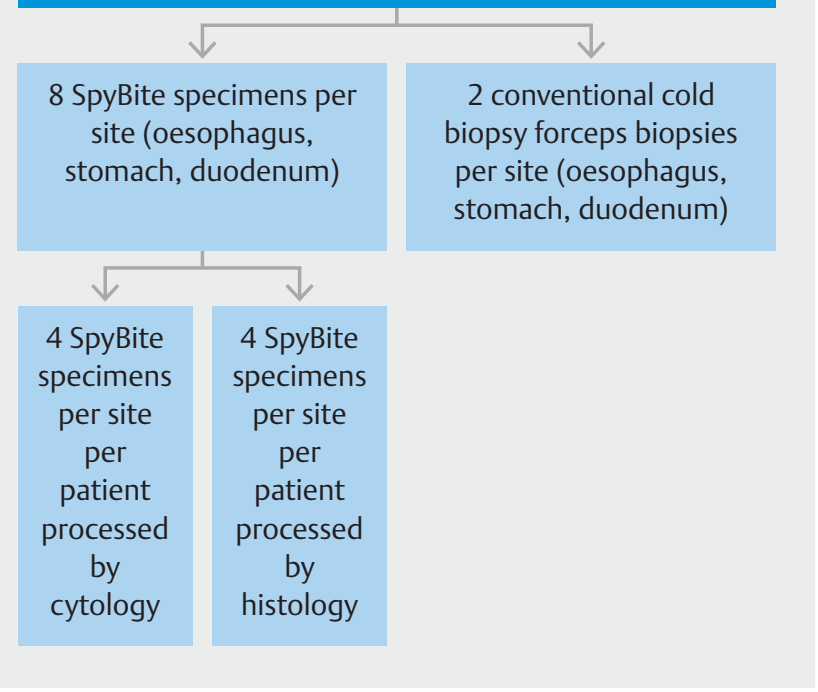

Fig. 1 Outline of methods for Phase one.

tive bleeding, variceal surveillance, or any therapeutic indication were excluded as well as those who were unable to give informed consent.

\section{Endoscopic procedure}

In each patient, eight SB specimens were obtained from the esophagus, stomach, and duodenum (in total 24 biopsies). The SB forceps was deployed through the working channel of an adult gastroscope. Four of these specimens from each site were processed by cytological CB preparation and the remaining four specimens from each site were processed by standard formalin fixation and paraffin embedding ( $>$ Fig. 2 ). Two additional conventional cold forceps biopsies (CFB) from each site (esophagus, stomach and duodenum) were obtained for processing by routine histopathological techniques, which formed the "gold-standard". Routine biopsies were taken using the single-use Radial Jaw four biopsy forceps (Boston Scientific Endoscopy, Natick, Massachusetts, United States).

\section{Specimen processing}

CB processing involved centrifugation of specimens at $2000 \mathrm{rpm}$ for 5 minutes followed by resuspension in human plasma and diluted thromboplastin/fibrinogen in a $1: 3 \mathrm{~mL}$ ratio with distilled water. Cellblocks were then fixed in 3 to $5 \mathrm{~mL}$ of $10 \%$ neutral buffered formalin and placed in printed tissue cassettes to be processed for histology and cut. Standard formalin fixation and paraffin embedding was used to process the SB and CFB specimens for histology.

\section{Data collection}

All specimens were assessed by a single pathologist, who was blinded to the site of biopsy as well as the patient's identity and clinical details. Specimens were assessed for ease of processing using a semi-quantitative scoring system, fragment 


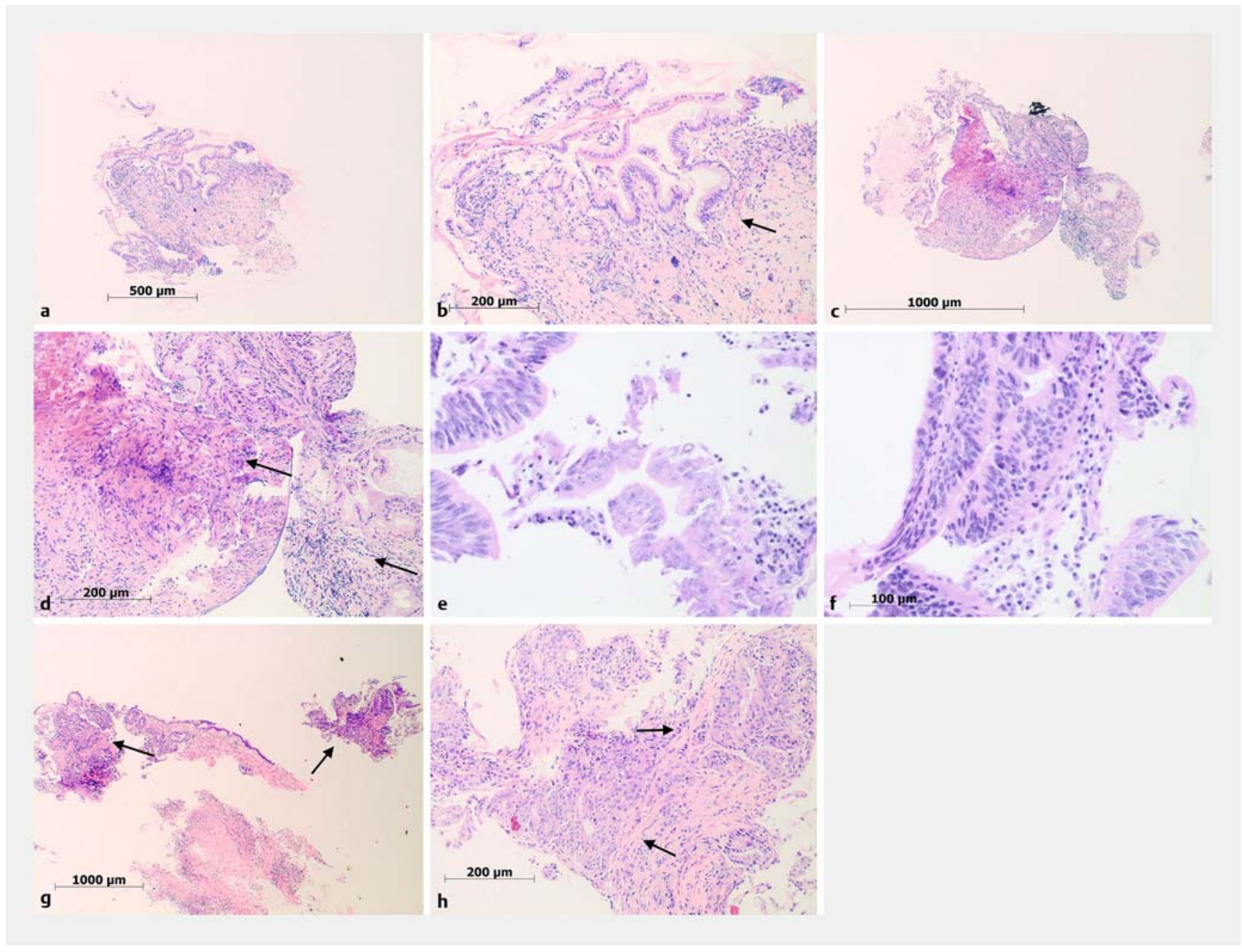

- Fig. 2 Sample processing. Low (a) and high power (b) of biliary cell block processed samples consistent with reactive epithelial changes (a, arrow). Biliary biopsy histologically processed samples showing inflammation and fibrosis (c, $\mathbf{d}$ arrows), high grade dysplasia (e, $\mathbf{f}$ arrows) and adenocarcinoma ( $\mathbf{g}, \mathbf{h}$ arrows)

size and number, site, diagnosis and presence of artefacts ( $\triangleright$ Table 3 ). After completion of specimen assessment, samples were de-identified and compared with the gold-standard CFB.

\section{Phase two}

Patient population

In phase two, consecutive patients undergoing SG cholangioscopy for diagnosis of indeterminate biliary lesions with the intention of obtaining targeted biopsies were included after obtaining informed consent. If a mass or stricture was defined SB biopsies were obtained and sent for CB processing.

\section{Endoscopic procedure and specimen processing}

All patients underwent extensive diagnostic assessment prior to cholangioscopy. Endoscopic retrograde cholangiopancreatogram (ERCP) and SG were performed in the standard fashion to delineate the stricture. If sphincterotomy had not been performed previously, it was performed before the cholangioscopy. Spyglass DS was used in all cases. Biliary stricture dilation was performed as needed to facilitate the passage of the cholangioscope. The cholangioscope was passed proximal to the lesion, suction was used to clear bile and contrast material, sterile saline solution was infused to optimize imaging, and the cholangioscope was slowly withdrawn to perform a systematic inspection of the ductal mucosa prior to targeted biopsies. Optical features suspicious for neoplasia were assessed, including adherent mucous, papillary projections, and irregular and prominent/dilated vessels [16-19]. All phase two (biliary) SB biopsy samples were processed using the described CB method.

\section{Data collection}

Specimens were assessed for ease of processing using a semiquantitative scoring system, fragment number and size, site, diagnosis and presence of artifact. Outcomes were compared with those of $C B$ luminal specimens from phase one. 
- Table 1 Patient demographics.

\begin{tabular}{|l|l|l|l|}
\hline & Phase 1 & Phase 2 & P value \\
\hline Mean age (years, SD) & $59.7(18.7)$ & $63(12.7)$ & NS \\
\hline Gender (\% female) & 40 & 91 & NS \\
\hline Indications & & \\
\hline - Indeterminate stricture & & 8 & \\
\hline - Mass lesion & & 3 & \\
\hline NS, not significant; SD, standard deviation & & \\
\hline
\end{tabular}

\section{Statistical analysis}

Statistical analysis was performed using GraphPad Prism version 7.00 for Macintosh, GraphPad Software, La Jolla, California, United States. Chi-square tests were used to test for independence between two categorical variables with expected frequencies greater than two, and two-tailed Fisher exact tests for input variable less than two. T-tests were used for comparing the means of independent variables. $P$ values $\leq 0.05$ were considered statistically significant. Descriptive statistics were calculated with reported mean and standard deviation.

This study was performed in accordance with the Declaration of Helsinki and was approved by our local ethics committee (Sydney Local Health District, Research Ethics and Governance Office, Ethics Approval Number X14-0243).

\section{Results}

\section{Phase one}

\section{Patient characteristics}

In total, 10 consecutive patients (mean age $59.7 \pm 18.7$ years, $40 \%$ female) presenting for outpatient upper gastrointestinal endoscopy were enrolled. Patient demographics are listed in
- Table 1. Diagnoses that were established included gastric intestinal metaplasia $(n=4)$, reflux esophagitis $(n=2)$, and coeliac disease $(n=1)$. Examination and biopsy were normal in the remaining 3 patients.

\section{Endoscopic procedures}

Gastrointestinal endoscopy was performed in all patients. In total, 240 SB biopsies were taken, of which 120 SB specimens (40 esophageal, 40 gastric, and 40 duodenal) were allocated to $C B$ processing, and 120 SB specimens to histology. No immediate or delayed adverse events relating to SB biopsy or endoscopy and sedation were reported.

\section{Tissue processing outcomes}

In total, the examining pathologist tallied 227 SB biopsies from the upper gastrointestinal tract, 105 in the CB group and 122 in the histology group. The characteristics are listed in $\mathbf{D}$ Table 2. The mean number of specimens recorded per site per patient was $3.6( \pm 0.86)$ in those processed by CB and $4.1( \pm 0.58)$ in those processed by histology $(P>0.05)$. Specimen size was significantly larger in the histology group compared to the cytology group $(2.02 \mathrm{~mm}( \pm 0.55)$ vs $1.49 \mathrm{~mm}( \pm 0.49), P<0.001$. The site of origin of specimens was correctly identified in $100 \%$ histology and $97 \%$ of CB specimens $(P=0.200)$. In the CB group, 11 out of 105 samples (10\%) had a crush artifact compared with 37 out of $122(30.3 \%)$ histology samples $(P=0.052)$. There was no significant difference between the two methods in the frequency of specimen processing difficulty per patient.

\section{Phase two}

Patient characteristics

In the biliary cohort, 11 patients (mean age $63.0 \pm 12.7$ years, $91 \%$ female) with indeterminate biliary lesions underwent assessment with SG cholangioscopy ( Table 1). In total, eight

- Table 2 Comparison of cell block and histology in luminal samples (Phase 1).

\begin{tabular}{|c|c|c|c|}
\hline & \multicolumn{3}{|l|}{ Phase 1} \\
\hline & Cell block & Histology & $P$ value \\
\hline No. patients biopsied & 10 & 10 & \\
\hline Total no. biopsies & 105 & 122 & \\
\hline Mean specimen size in mm (SD) & $1.49(0.49)$ & $2.02(0.55)$ & $<0.001$ \\
\hline Mean no. biopsies per patient per site (SD) & $3.57(0.86)$ & $4.1(0.58)$ & NS \\
\hline $\begin{array}{l}\text { Correct Identification } \\
\text { of site (\%) }\end{array}$ & $29 / 30(97 \%)$ & $30 / 30(100 \%)$ & NS \\
\hline \multicolumn{4}{|l|}{ Tissue processing difficulties } \\
\hline - Tissue transfer (\%) & $2 / 30(7 \%)$ & $3 / 30(10 \%)$ & NS \\
\hline - Paraffin embedding (\%) & $8 / 30(27 \%)$ & $4 / 30(13 \%)$ & NS \\
\hline Crush artifacts (\%) & $3 / 30(10 \%)$ & $9 / 30(30 \%)$ & NS \\
\hline
\end{tabular}


- Table 3 Comparison of Luminal CB Specimen (Phase 1) and Biliary CB Specimen (Phase 2)

\begin{tabular}{|l|c|c|c|}
\hline & Luminal cell block & Biliary cell block & P value \\
\hline No.patients biopsied & 10 & 6 \\
\hline Total no. biopsies & 105 & 20 \\
\hline Mean no. biopsies per patient per site (SD) & $3.57(0.86)$ & $3.3(0.77)$ & NS \\
\hline Mean specimen size in mm (SD) & $1.49(0.49)$ & $1.1(0.74)$ & NS \\
\hline Adequate tissue for diagnosis (\%) & $29 / 30(97 \%)$ & $11 / 11(100 \%)$ & NS \\
\hline Crush artifacts (\%) & $3 / 30(10 \%)$ & $2 / 11(18 \%)$ & NS \\
\hline NS, not significant & & & \\
\hline
\end{tabular}

patients had a suspected indeterminate stricture and three patients had a suspected mass.

\section{Endoscopic procedures}

In all cases, SG cholangioscopy was performed by the method described. In five of 11 patients, no biopsies were taken due to the following reasons: mucosa appeared normal on SG cholangioscopy $(n=3)$, stone was found (no mass) $(n=1)$, extensive cholangiocarcinoma was seen and biopsies were not indicated $(n=1)$. In six of 11 patients, visually targeted SB biopsies were taken: five patients had a stricture ( 3 distal and 2 hilar), and one had a Paris Ips mass lesion of the common bile duct (CBD). Two lesions had optical features suspicious for neoplasia: the CBD Paris Ips lesion had adherent mucous, papillary projections, and irregular and prominent vessels and one of the hilar strictures had papillary projections and dilated and interrupted vessels. In total, 20 SB biopsies were sampled in six patients (mean number of specimens per site $3.3 \pm 0.77$ ), and all were processed by $\mathrm{CB}$. There were no immediate or delayed adverse events.

\section{Tissue processing outcomes}

In total, 20 specimens from six patients were assessed by our pathologist. The number of SB varied between one to six specimens per patient with a median of four specimens.

Mean size of biliary specimens processed by CB was $1.1 \mathrm{~mm}$ $( \pm 0.74)$. Tissue was deemed adequate for diagnosis in all six patients (100\%). Histopathological diagnoses made were chronic inflammation $(n=2)$, cholangiocarcinoma $(n=1)$, high-grade dysplasia $(n=1)$, primary sclerosing cholangitis $(n=1)$, and normal tissue $(n=1)$. Minimum clinical follow up for this group was 7 months. The diagnosis of cholangiocarcinoma was established in the above-mentioned hilar stricture with optical features suspicious for malignancy. The CBD paris Ips lesion was assessed to be high-grade dysplasia. Crush artefact was reported in one case (17\%), however, this sample was otherwise well preserved and remained of diagnostic quality. The differences in specimen size and frequency of artefact between CB batches in the lumen (phase one) and bile duct (phase two) did not reach significance ( $>$ Table 3 ).

\section{Discussion}

This prospective pilot study compared two different processing techniques for SpyBite tissue specimens in the analysis of upper gastrointestinal specimens which was then extrapolated to patients with indeterminate biliary strictures. The available modalities for tissue diagnosis in indeterminate biliary strictures remain suboptimal, and the optimal method for processing SB specimens has not been previously established [22]. The small size of specimens yielded is an important factor $[23,24]$. This study shows that CB is non-inferior to histological analysis in both foregut biopsies as well as the analysis of biliary lesions, despite the significantly smaller specimen size on those processed by CB. Importantly. there was a trend towards less crush artifacts in the $C B$ samples than in the histology samples.

The reason for smaller specimen size in our CB cohort compared with the histology group $(1.49 \mathrm{~mm}$ vs $2.02 \mathrm{~mm}, P<0.001)$ likely relates to processing factors. CB allows for processing of small fragments, and has a well-established role in EUS fineneedle aspiration (EUS-FNA) where tiny specimen fragments are not able to be processed histologically. In our cohort there was a trend for the biliary specimens to be smaller than those from the foregut lumen $(1.1 \mathrm{~mm}$ vs $1.49 \mathrm{~mm}, P>0.05)$. This could be explained by selection bias, as the foregut tissues were mostly healthy tissue whereas the biliary samples were all from diseased tissue and often fibrotic. Moreover, the tangential biopsy acquisition in the bile duct could play an important role in this smaller size of the specimens. In general, the specimens from a standard forceps biopsy are 2 to $3 \mathrm{~mm}$ each in greatest dimension and crush artifact is usually either absent, focal, or mild.

We showed a discrepancy in the SB samples numbers in phase one, with the protocolized 240 luminal SB samples collected at endoscopy and 227 samples counted by the reviewing pathologist. Of the four specimens acquired per site, a mean of 3.6 per site were reported in CB and 4.1 per site in histology. This could be explained by clumping of specimens in the $C B$ batches and fragmentation in the histology batches.

Our study has several limitations. First, it had a small sample size albeit this was a feasibility study. Second, the biopsies were only assessed by a single pathologist. Although the pathologist is an expert in the field, this might lead to observer bias. This 
effect was minimized by blinding the pathologist to the site of the biopsies and clinical details. Finally, our study did not include a comparison between histology and CB methods in the bile duct. If the trend to smaller specimens from the bile duct compared with foregut (1.1 vs $1.5 \mathrm{~mm}$, respectively) was also seen in the histology specimens, one may expect increased processing difficulties. Such difficulties with histology have previously been reported, however, in our pilot study there was no difference in difficulty of processing the material per patient $[21,25,26]$.

This pilot study suggests a possible method for tissue handling to overcome the processing difficulties with SpyBite specimens. Based on the positive results of our study, a randomized controlled trial comparing histology and $C B$ within the $C B D$ is indicated to further establish the role for this processing method. Alternate processing techniques have been reported. A recent publication reported successful application of rapid onsite evaluation (ROSE), a technique often seen in EUS-FNA, in SB biliary specimens [25]. This technique yielded a sensitivity for malignancy of $100 \%$, though interestingly the specificity dropped to $88.9 \%$. Future studies should address the optimal processing technique, considering also institutional factors such as case volume and cytology expertise.

\section{Conclusion}

In conclusion, processing Spybite specimens via cellblock cytology was comparable to histology in the analysis of foregut biopsies and indeterminate biliary strictures. This study is a first step in establishing the role of this technique in the analysis of indeterminate strictures.

\section{Competing interests}

Support was received from Boston Scientific for expendable equipment and the SpyBite biopsy forceps used for the patients in Phase 1 were supplied free of charge

\section{References}

[1] Tummala P, Munigala S, Eloubeidi MA et al. Patients with obstructive jaundice and biliary stricture \pm mass lesion on imaging: prevalence of malignancy and potential role of EUS-FNA. J. Clin. Gastroenterol 2013; 47: $532-537$

[2] Corvera CU, Blumgart LH, Darvishian F et al. Clinical and pathologic features of proximal biliary strictures masquerading as hilar cholangiocarcinoma. J Am Coll Surg 2005; 201: 862 - 869

[3] Kwok KH, Rizk J, Coleman M et al. Pancreaticoduodenectomy - outcomes from an Australian institution. ANZ J Surg 2010; 80: 605-608

[4] Korc P, Sherman S. ERCP tissue sampling. Gastrointest Endosc 2016; 84: $557-571$

[5] Jailwala J, Fogel EL, Sherman $\mathrm{S}$ et al. Triple-tissue sampling at ERCP in malignant biliary obstruction. Gastrointest Endosc 2000; 51: $383-$ 390

[6] Kitajima Y, Ohara H, Nakazawa T et al. Usefulness of transpapillary bile duct brushing cytology and forceps biopsy for improved diagno- sis in patients with biliary strictures. J Gastroenterol Hepatol 2007; 22: $1615-1620$

[7] Howell DA, Parsons WG, Jones MA et al. Complete tissue sampling of biliary strictures at ERCP using a new device. Gastrointest EndosC 1996; 43: $498-502$

[8] Sugiyama M, Atomi Y, Wada $\mathrm{N}$ et al. Endoscopic transpapillary bile duct biopsy without sphincterotomy for diagnosing biliary strictures: a prospective comparative study with bile and brush cytology. Am J Gastroenterol 1996; 91: 465-467

[9] Farrell RJ, Jain AK, Brandwein SL et al. The combination of stricture dilation, endoscopic needle aspiration, and biliary brushings significantly improves diagnostic yield from malignant bile duct strictures. Gastrointest Endosc 2001; 54: 587-594

[10] De Bellis M, Fogel EL, Sherman S et al. Influence of stricture dilation and repeat brushing on the cancer detection rate of brush cytology in the evaluation of malignant biliary obstruction. Gastro-intest Endosc 2003; 58: $176-182$

[11] Bergquist A, Tribukait B, Glaumann $\mathrm{H}$ et al. Can DNA cytometry be used for evaluation of malignancy and premalignancy in bile duct strictures in primary sclerosing cholangitis? J Hepatol 2000; 33: 873 7.70

[12] Navaneethan U, Hasan MK, Lourdusamy V et al. Single-operator cholangioscopy and targeted biopsies in the diagnosis of indeterminate biliary strictures: a systematic review. Gastrointest Endosc 2015; 82 : $608-614$

[13] Rösch T, Hofrichter K, Frimberger E et al. ERCP or EUS for tissue diagnosis of biliary strictures? A prospective comparative study Gastrointest Endosc 2004; 60: 390-396

[14] Byrne MF, Gerke H, Mitchell RM et al. Yield of endoscopic ultrasoundguided fine-needle aspiration of bile duct lesions. Endoscopy 2004; 36: $715-719$

[15] Meara R, Jhala D, Eloubeidi MA et al. Endoscopic ultrasound-guided FNA biopsy of bile duct and gallbladder: analysis of 53 cases. Cytopathology 2006; 17: $42-49$

[16] Mounzer R, Austin GL Wani S et al. Per-oral video cholangiopancreatoscopy with narrow-band imaging for the evaluation of indeterminate pancreaticobiliary disease. Gastrointest Endosc 2017; 85: 509 517

[17] Keegan M], Singh R, Lim P et al. Which Optical Features Differentiate Benign and Neoplastic Biliary Lesions As Assessed by Balloon Assisted Cholangioscopy? Gastrointest Endosc 2015; 81: 188

[18] Sethi A, Shah RJ, Itoi T et al. Defining Imaging Criteria for Indeterminate Biliary Strictures Utilizing Video Cholangioscopy: the Monaco Classification. Gastrointest Endosc 2015; 81: 188 - 189

[19] Behary J, Keegan MJ, Wu P et al. Validation of specific optical features to differentiate benign from neoplastic biliary strictures as assessed by balloon-assisted cholangioscopy. Gastrointest Endosc 2016; 83: 602

[20] Itoi T, Osanai M, Igarashi Y et al. Diagnostic peroral video cholangioscopy is an accurate diagnostic tool for patients with bile duct lesions. Clin Gastroenterol Hepatol 2010; 8: 934-938

[21] Ramchandani M, Reddy DN, Gupta R et al. Role of single-operator peroral cholangioscopy in the diagnosis of indeterminate biliary lesions: a single-center, prospective study. Gastrointest Endosc 2011; 74: $511-519$

[22] Njei B, McCarty TR, Varadarajulu S et al. Systematic review with metaanalysis: endoscopic retrograde cholangiopancreatography-based modalities for the diagnosis of cholangiocarcinoma in primary sclerosing cholangitis. Aliment Pharmacol Ther 2016; 44: 1139-1151

[23] Hoffman A, Rey JW, Kiesslich R. Single operator choledochoscopy and its role in daily endoscopy routine. World J Gastrointest Endosc 2013; 5: $203-210$ 
[24] Tabibian JH, Visrodia KH, Levy M] et al. Advanced endoscopic imaging of indeterminate biliary strictures. World J Gastrointest Endosc 2015; 7: $1268-1278$

[25] Varadarajulu S, Bang JY, Hasan MK et al. Improving the diagnostic yield of single-operator cholangioscopy-guided biopsy of indetermi- nate biliary strictures: ROSE to the rescue? (with video) Gastrointest Endosc 2016; 84: 681 - 687

[26] Hartman DJ, Slivka A, Giusto DA et al. Tissue yield and diagnostic efficacy of fluoroscopic and cholangioscopic techniques to assess indeterminate biliary strictures. Clin Gastroenterol Hepatol 2012; 10: $1042-1046$ 